\title{
EDITORIAL
}

\section{DESAFIOS E PROPOSIÇÕES PARA A FORMAÇÃO DOCENTE}

O número 109 encerra o volume 34 da Revista Contexto \& Educação com 15 artigos. Cinco deles constituem a sessão Educação, Ambiente e Saúde ao tematizarem aspectos da formação profissional e estratégias de ensino. Nos outros dez artigos da demanda espontânea os autores apresentam reflexões sobre desafios e proposições para a formação docente desde a perspectiva de valores, inclusão, educação científica, ensino de Geografia e Matemática. A diversidade de abordagens e referenciais instiga outros estudos sobre estes temas, que parecem tão próximos, ao mesmo tempo em que estabelecem propostas singulares de pesquisa.

\section{EDUCAÇÃO, AMBIENTE E SAÚDE}

Esta seção inicia-se com a formação do professor de Educação Ambiental, passando por aspectos da formação de docentes e de estratégias de desenvolvimento da Educação em Saúde.

Rosangela Inês Matos Uhmann e Luciane Follmann, no artigo A perspectiva do professor na educação ambiental, relatam as discussões de algumas concepções e práticas pedagógicas sobre o tema, num processo de formação continuada entre licenciandos, formadores e professores de escola. Os dados foram construídos mediante análise dos discursos dos participantes dos Ciclos Formativos em Ensino de Ciências, no encontro que tratou das "Questões controversas em uma perspectiva crítica da Educação Ambiental que podem ser abordadas em sala de aula". Além dos aspectos documentais no estudo das leis ambientais, imagens (cartuns) foram utilizadas para trabalhar com as questões socioambientais na Educação Básica.

Tatiane Motta da Costa e Silva, Caroline Andressa Bortoluzzi Zalamena e Rodrigo de Souza Balk, no artigo Educação inclusiva e redes de apoio: reflexões a partir de uma realidade escolar, analisaram o contexto de uma escola pública, a fim de identificar as estratégias de articulação e atendimento às/aos alunas/os com deficiência. Trata-se de um estudo qualitativo, caracterizado como uma pesquisa descritiva. O procedimento de coleta de dados ocorreu por meio da observação participante no ambiente escolar e em locais próximos à escola, e de entrevista semiestruturada com a coordenadora pedagógica da escola e com a gestora da Estratégia de Saúde da Família (ESF) adstrita. A escola possui 1.290 alunas/os, e, destes, 53 apresentam alguma deficiência. A articulação entre a escola e a ESF ocorre por meio do Programa Saúde na Escola (PSE) e mediante o encaminhamento das/os alunas/os para atendimento no serviço de saúde.

No artigo, $A$ interculturalidade na formação dos profissionais de enfermagem, Rosane Teresinha Fontana propõe uma reflexão sobre a questão, utilizando a revisão narrativa como método. A interculturalidade configura uma nova perspectiva epistemológica e objeto de estudo interdisciplinar transversal. O estudo tematiza a complexidade na formação em Enfermagem e como esta pode agregar valor ao cuidado. Em todas as áreas do conhecimento a diversidade cultural só pode ser promovida ao reconhecer, como princípio fundador, o diálogo e o respeito entre as civilizações e as culturas. 
Daniela Sastre Rossi Visintainer e Félix Alexandre Antunes Soares, no artigo $O$ desenvolvimento de estratégias de ensino para a promoção da saúde na formação docente continuada, utilizam a pesquisa-ação para investigar a contribuição de oficinas pedagógicas sobre a promoção da saúde na formação docente continuada. Este trabalho tem como objetivo analisar o desenvolvimento de estratégias de ensino e aprendizagem contextualizadas com o tema promoção da saúde a partir da percepção dos professores. Constataram que a contextualização do tema favoreceu o processo de ensino e aprendizagem e a mudança de hábitos em relação à saúde.

No artigo Educação em saúde, mediada por filme comercial, na formação de professores de ciências da natureza, Eliane Gonçalves dos Santos; Maria Cristina Panserade-Araújo e Graça Simões de Carvalho partem dos pressupostos de que as mudanças curriculares, a inserção das novas tecnologias, o contexto social e as condições econômicas e políticas da sociedade moderna afetam o processo de formação de professores. Discutem e significam a Educação em Saúde (ES), na formação inicial e continuada de professores, com uso do filme comercial "Uma Prova de Amor" (EUA, 2009), a partir da questão: Que aprendizagens em Educação em Saúde são produzidas na discussão de filmes comerciais, em aulas da educação básica ou superior? Vinte e seis professores de Ciências Biológicas, em formação inicial e continuada, com reuniões formativas sistemáticas, participaram de sete sessões fílmicas. Em cada uma delas o grupo assistia a um filme e discutia as compreensões de saúde e educação em saúde. A Análise Microgenética das transcrições das discussões produzidas mostrou que o debate e as interações no grupo possibilitaram ampliar e ressignificar o entendimento de saúde numa articulação de aspectos anatômicos, fisiológicos e bioquímicos, sociais, emocionais e ambientais.

A demanda espontânea inicia-se com o artigo Educação em valores morais numa perspectiva transdisciplinar, no qual Daniel Skrsypcsak e Douglas Orestes Franzen refletem sobre a questão, numa perspectiva transdisciplinar, em que estendem a discussão a partir das instituições, que oferecem a educação pública básica. Os autores estruturaram o artigo em três momentos: 1) considerações em relação à ética sob o ponto de vista da complexidade de Edgar Morin; 2) conceitos sobre a transdisciplinaridade com Basarab Nicolescu, e 3) problematizam os valores morais na escola pública, buscando na transdisciplinaridade uma possibilidade de discussão. Defendem a elaboração de um projeto institucional, em que as ações e relações da escola tenham os valores morais explicitados de forma consciente e intencional.

Roberta Pasqualli; Vosnei da Silva e Adriano Larentes da Silva, no artigo intitulado Limites e potencialidades de materialização do currículo integrado: uma análise dos planos de ensino e diários de classe, objetivaram identificar e compreender os limites e potencialidades de materialização do currículo integrado no cotidiano dos cursos Técnico em Informática Integrado ao Ensino Médio, Campus Chapecó, e Técnico em Agroindústria Integrado ao Ensino Médio, Campus São Miguel do Oeste, ambos ofertados pelo Instituto Federal de Educação, Ciência e Tecnologia de Santa Catarina - IFSC. O foco da análise foram 13 Planos de Ensino e 10 Diários de Classe dos componentes curriculares Oficina de Integração e Projeto Integrador, do primeiro e segundo semestres de 2015. 
Os resultados da análise mostram a complexidade do trabalho pedagógico no contexto do currículo integrado e apontam para diferentes formas de materialização da integração nas Oficinas de Integração e nos Projetos Integradores.

No artigo, Temas e conteúdo do jogo de papéis: sinalizando caminhos para a atuação pedagógica com a atividade lúdica na educação infantil, Dóris de Jesus Moya, Marta Sueli de Faria Sforni e Paula Tamyris Moya afirmam, desde a Teoria Histórico-Cultural, que a atividade lúdica é fundamental no desenvolvimento psíquico da criança. Realizaram uma pesquisa de caráter bibliográfico, centrada na produção de Leontiev e Elkonin, que se ocuparam do estudo do desenvolvimento psíquico e da periodização do desenvolvimento infantil. Elkonin afirma que o jogo de papéis é a atividade lúdica que maior impacto exerce no desenvolvimento de crianças na faixa etária, que corresponde ao final da Educação Infantil. Por meio da compreensão dos elementos (tema e conteúdo) é possível reconhecer que nas instituições educativas, além de se reservar tempo e espaço para esse tipo de atividade lúdica, é preciso atuar pedagogicamente no seu conteúdo.

Giselly dos Santos Peregrino e Alessandra Gomes da Silva, no artigo Interculturalidade em That Deaf Guy: uso de tiras para problematização de estereótipos e preconceitos contra sujeitos surdos e sua língua de sinais, problematizam estereótipos e preconceitos contra as pessoas surdas e a língua de sinais, a partir do viés do próprio sujeito da experiência e do humor como estratégia para a desconstrução de ideias preestabelecidas e não ressignificadas.

No artigo Utilização de modelos didáticos tateáveis como metodologia para o ensino de biologia celular em turmas inclusivas com deficientes visuais, Angela Michelotti e Elgion Lucio da Silva Loreto propõem alternativas aos alunos para visualizarem, manipularem, tocarem em modelos que representem as verdadeiras estruturas celulares, auxiliando o aprendizado. Neste estudo, testaram a hipótese de que modelos tridimensionais de diversos tipos celulares, assim como de processos envolvendo células (multiplicação celular e cicatrização), utilizados inicialmente de forma tátil, podem ser uma ferramenta eficiente para o ensino de biologia celular em uma perspectiva de inclusão de alunos com Necessidades Educacionais Especiais.

A formação interdisciplinar de licenciandos em ciências da natureza e o aprendizado das ciências do céu, de autoria de Gisele Soares Lemos Shaw e João Batista Teixeira da Rocha, apresenta a investigação do processo com três licenciandos em Ciências da Natureza durante uma oficina de Astronomia desenvolvida com estudantes do Ensino Fundamental. Por meio da análise textual discursiva de dados provindos de questionário, formulário de planejamento da oficina, projeto da oficina, planos de aula, anotações sobre a apresentação verbal da experiência, relato da experiência em formato de artigo, formulário autoavaliativo e entrevista, foram analisados conhecimentos e habilidades interdisciplinares desenvolvidos por esses licenciandos.

Fatima Passos Kanitar e Rosália Maria Duarte, no artigo Literacia de informação no ensino médio: referencial para pesquisa de informação científica, abordam as competências de pesquisa, seleção e tratamento de informação científica, com recurso às Tecnologias de Informação e Comunicação. Mostram as alterações realizadas no refe- 
rencial de avaliação dessas competências com estudantes do Ensino Superior, da área de Educação, com vistas à formação de estudantes do Ensino Médio Técnico, da área de mecânica, e o seu uso nesse contexto.

No artigo $O$ ensino da geografia aplicado à lei 10.639, Pedro Dias Mangolini Neves e Aldenir Dias dos Santos apresentam o projeto de intervenção pedagógica desenvolvido na Escola Municipal Professora Geni Chaves, localizado no município de Uberaba, Minas Gerais, com o envolvimento de alunos, professores e equipe pedagógica no nível Ensino Fundamental II (6 a 9o anos) tendo como foco o tratamento para a educação das relações étnico-raciais de forma positiva, bem como o estudo da história e cultura afro-brasileira e africana.

Willian Simões e Adriana Maria Andreis, no artigo, Anoitece na cidade: dilemas e desafios do ensino médio noturno em tempos de reforma, debatem os resultados de uma pesquisa com estudantes (1.913), professores (103) e gestores (48) do Ensino Médio (EM) noturno, de escolas públicas estaduais de Chapecó/SC, sobre os dilemas e desafios do Ensino Médio noturno, em particular de fatores que influenciam direta ou indiretamente nos índices de evasão/abandono e repetência por parte dos estudantes.

No artigo Realismo crítico e marxismo: contribuições à filosofia da educação matemática, Guilherme Wagner e Everaldo Silveira procuram elucidar pontos nodais do Realismo Crítico com relação às compreensões de verdade científica e progresso da ciência, explicando conceitos-chave como estratificação e emergência da realidade, relativismo epistemológico, ontologia e julgamento racional. Realizaram um estudo da primeira fase da obra de Roy Bhaskar, fundador da corrente filosófica, na qual se percebe as grandes potencialidades para o campo educacional das Ciências e da Matemática, haja vista seu caráter unificador.

Encerramos esta apresentação com o convite para a leitura dos artigos disponibilizados, os quais certamente possibilitarão novas aprendizagens.

Boa leitura.

Maria Cristina Pansera de Araújo 